\section{Isolations of micro-organisms from arthritic patients and healthy normals}

Sir,

I would like to bring to the attention of your readers the provision of an essential control for the numerous isolations that have been reported of micro-organisms from the blood and joint fluids of arthritic subjects, and many more such observations that have been made but not published because of the difficulty of establishing any causal relationship. It has now been shown in this laboratory that one of the most important organisms can be detected regularly, after prolonged periods of incubation, in the blood of normal subjects, but at a very much lower incidence than in the blood and joint fluids of arthritic subjects.

In most cases (Benedek, 1955; Duthie et al., 1967; Markham and Myers, 1976) the isolates have not been properly identified in bacteriological terms, but vaguely described as a bacillus, diphtheroid, or mycoplasma. By contrast, Pease (1974) identified an L-form of Bacillus licheniformis, but clearly distinguishable from saprophytic strains. It may fairly be called $B$. licheniformis (var. endoparasiticus, Benedek). This confirmed the identification of Roberts (1964) from arthritis in turkeys. The outstanding characteristic of the organism is that during an exceedingly prolonged period of incubation, in the process of reversion to the Bacillus from the L-form, it passes through a stage in which it resembles a Corynebacterium or Mycobacterium (i.e. diphtheroid) and thus reproduces all the different morphologies that have been attributed to various unclassified isolates. This very protean behaviour has been fully described in the past by American workers dealing mainly with strains derived, not from arthritis, but from neoplastic disease (Annals of the New York Academy of Sciences, 1970).

The concept that infection with habitually nonpathogenic micro-organisms may be a factor in autoimmune disease, including rheumatoid arthritis, possibly by causing a failure in immunological recognition of affected tissues (Pease, 1965, see also for references), has become progressively acceptable in recent years (Brown et al., 1974; Mattman, 1974). However, a very serious deficiency in the existing evidence has been the lack of a control series of isolations showing the distribution of such organisms in healthy subjects. The mere assumption that normal blood is sterile is not acceptable.

In this laboratory we are in the process of completing such a study which, because it is for the most part pure bacteriology, is not appropriate for full publication in this journal; but because it provides the missing control on isolations previously published here, should nevertheless be available to rheumatologists, and that is the purpose of this letter.

Blood cultures were made from 126 subjects in Birmingham and Ancona, Italy, using a system of repli- cates and cross-controls to avoid suspicion of contamina- $-\frac{\bar{m}}{\circ}$ tion during the 8 months in which the primary cultures $\varrho$ were incubated. The isolation techniques followed wereg those of Pease $(1969,1970)$ and Tedeschi et al. $\left(1975\right.$, and ${ }^{\text {s }}$ other previous papers). At intervals of up to 8 months' $\overrightarrow{0}$ incubation, the L-form of the organism was isolated, in $\overrightarrow{-}$ various stages of reversion from a spheroplast to an acid- $\vec{\omega}$ fast 'diphtheroid' and eventually a bacillus, from $25 \%$ of samples of whole blood or blood cells, but only fromo about $2 \%$ of platelet-rich plasmas. This bears out thew contention of Pease $(1969,1970,1974)$ that the infection: is associated with the erythrocytes, but it also showsio that, whereas it is unquestionably present in healthyo persons, its detectable incidence is only a small proportions of the almost $100 \%$ found in arthritis, although non-cultivable L-forms are probably more numerous still. T

It is submitted that this is an observation of the utmosto practical importance in the investigation of the aetiology of arthritis, whatever its significance may prove to be.

As a coda, I am glad to be able to report, in view of the valuable assistance give to me by Professor Guido 9 Tedeschi, of the University of Camerino, that $15 \%$ of. plasma cultures eventually grew a Gram-positive coccus, which substantiates his claim that the L-form of these organisms is associated with the platelets of a similar percentage of normal persons. There is however, noo suggestion that such cocci are a significant factor ino arthritis, as B.1. endoparasiticus almost certainly is; the finding merely emphasizes the existence of cryptic L-form $\overrightarrow{\vec{\sigma}}$ infection in blood.

\section{Department of Bacteriology University of Birmingham, Birmingham B15 2TJ}

References

Annals of the New York Academy of Sciences (1970). Symposium. Unusual isolates from clinical material. IV Microorganisms associated with malignancy, 174, 636-785.

Benedek, T. (1955). Rheumatoid Arthritis and Psoriasis Vulgaris. Edwards, Ann Arbor, Michigan.

Brown, T. McP., Clark, H. W., and Bailey, J. S. (1974) Natural occurrence of rheumatoid arthritis in great apes a new animal model. Proceedings of the Zoological Societ $\mathrm{N}$ of the Philadelphia Centennial Symposium on Science and Research, pp. 43-49.

Duthie, J. J. R., Stewart, S. M., Alexander, W. R. M., and Dayhoff, R. E. (1967). Isolation of diphtheroid organisms from rheumatoid synovial membrane and fluid. Lancet, 1 142-143.

Markham, J. G., and Myers, D. B. (1976). Preliminaryo observations on an isolate from synovial fluid of patient with rheumatoid arthritis. Annals of the Rheumatic Diseases, 35, 1-7.

Mattman, L. (1974). Cell Wall Deficient Forms. CRC Press Cleveland, Ohio.

Pease, P. (1965). L-forms, Episomes and Autoimmune Disease $\mathbb{8}$ Livingstone, Edinburgh. 
Pease, P. (1969). Bacterial L-forms in the blood and joint fluids of arthritis subjects. Annals of the Rheumatic Diseases, 28, 270-274.

Pease, P. (1970). Morphological appearances of a bacterial L-form growing in association with the erythrocytes of arthritic subjects. Annals of the Rheumatic Diseases, 29, 439-444.

Pease, P. (1974). Identification of bacteria from blood and joint fluids of human subjects as Bacillus licheniformis. Annals of the Rheumatic Diseases, 33, 67-69.

Roberts, D. E. (1964). L-phase bacterial forms associated with infectious synovitis in chickens and turkeys. Research in Veterinary Science, 5, 441-449.

Tedeschi, G. G., Amici, D., and Santarelli, I. (1975). L- and conventional forms of micrococci in the circulating blood of thrombocytopenic patients. Experientia, 31, 1088-1089.

\section{Effect of anti-inflammatory agents on serum gastrin concentrations}

Sir,

We were interested in the paper by Rooney et al. (1976) showing that the raised serum immunoreactive gastrin concentration, which is frequently found in patients with rheumatoid arthritis, is not modified by 14 days' administration of anti-inflammatory drugs (aspirin, indomethacin, phenylbutazone, tetracosactrin, or ascorbic acid). Other workers have reported increased basal and/or mealstimulated serum gastrin levels after chronic corticosteroids or corticotrophin treatment, both in the dog (Watson et al., 1973) and in man (Raptis et al., 1976), while the basal serum gastrin concentration was not modified after acute parenteral administration of hydrocortisone (Watson et al., 1973; Giordano and Marugo, 1974) or prednisolone (Raptis et al., 1976). No data are available on the effects of acute administration of nonsteroidal anti-inflammatory drugs on serum gastrin levels. Therefore, we have evaluated the serum gastrin concentration after acute parenteral administration of phenylbutazone, lysine-acetylsalicylate, and hydrocortisone.
Twenty-seven healthy males aged 26-51 years volunteered for study. Each drug was administered after an overnight fast to 9 subjects as follows: hydrocortisone $100 \mathrm{mg}$ or lysine-acetylsalicylate $2 \mathrm{~g}(1.8$ acetylsalicylic acid) by rapid intravenous injection; phenylbutazone $600 \mathrm{mg}$ intramuscularly. The serum gastrin concentration was evaluated by the radioimmunoassay method before and 15,30,45, 60, and 90 minutes after treatment. The Table shows that the mean serum basal gastrin levels were not significantly modified by any drug.

Present data confirmed that acute hydrocortisone administration does not affect gastrin secretion and, together with the study by Rooney et al. (1976), show that acetylsalicylic acid and phenylbutazone fail to increase serum gastrin after acute as well as chronic treatment.

\section{Guglielmo Curtarelli, Roberto Caldara, and LUIGI BIERTI 2nd Department of Medicine, Fatebenefratelli Hospital, 23 Corso di Porta Nuova, 20121 Milan, Italy.}

\section{References}

Giordano, G., and Marugo, M. (1974). Comportamento della gastrina ematica nell'uomo dopo carico endovenoso di cortisolo. Bollettino della Società Italiana di Biologia Sperimentale, 50, 1905-1910.

Raptis, S., Berger, L., Dollinger, H. C., Fazekas, A. T., and Pfeiffer, E. F. (1976). Hypergastrinemia induced by glucocorticoid and corticotropin treatment in man. American Journal of Digestive Diseases,. 21, 376-380.

Rooney, P. J., Grennan, D. M., Sturrock, R. D., Brooks, P. M., and Dick, W. C. (1976). Serum immunoreactive gastrin: specificity for rheumatoid arthritis, bimodality of distribution, and failure of effect of anti-inflammatory drugs. Annals of the Rheumatic Diseases, 35, 40-45.

Watson, L. C., Reeder, D. D., and Thompson, J. C. (1973). Effect of hydrocortisone on gastric secretion and serum gastrin in dogs. Surgical Forum, 24, 354-356.

Table Effect of acute administration of anti-inflammatory agents on serum gastrin concentration in normal subjects $($ mean \pm SEM)

\begin{tabular}{|c|c|c|c|c|c|c|c|c|}
\hline \multirow[t]{2}{*}{ Treatment } & \multirow[t]{2}{*}{ No. of subjects } & \multicolumn{7}{|c|}{ Time (min) } \\
\hline & & -15 & 0 & 15 & 30 & 45 & 60 & 90 \\
\hline $\begin{array}{l}\text { Phenylbutazone } \\
\text { Lysine-acetylsalicylate } \\
\text { Hydrocortisone }\end{array}$ & $\begin{array}{l}9 \\
9 \\
9\end{array}$ & $\begin{array}{l}72 \pm 7 \\
80 \pm 5 \\
75 \pm 7\end{array}$ & $\begin{array}{l}71 \pm 8 \\
78 \pm 7 \\
73 \pm 7\end{array}$ & $\begin{array}{l}73 \pm 8 \\
80 \pm 8 \\
75 \pm 6\end{array}$ & $\begin{array}{l}76 \pm 9 \\
82 \pm 7 \\
79 \pm 10\end{array}$ & $\begin{array}{l}77 \pm 6 \\
80 \pm 9 \\
76 \pm 9\end{array}$ & $\begin{array}{l}70 \pm 9 \\
83 \pm 10 \\
78 \pm 7\end{array}$ & $\begin{array}{l}73 \pm 9 \\
79 \pm 8 \\
78 \pm 9\end{array}$ \\
\hline
\end{tabular}

